\title{
Robot-Assisted Transplant Surgery - Vision or Reality? A Comprehensive Review
}

\author{
Philipp Stiegler ${ }^{a}, \mathrm{~b} \quad$ Peter Schemmer ${ }^{\mathrm{a}} \mathrm{b}$ \\ ${ }^{a}$ Division of Transplant Surgery, Department of Surgery, Medical University of Graz, Graz, Austria; \\ ${ }^{\mathrm{b}}$ Transplant Center Graz, Medical University of Graz, Graz, Austria
}

\section{Keywords}

Robotic-assisted organ transplantation .

Robotic-assisted organ retrieval - Liver transplantation . Kidney transplantation - Pancreatic transplantation

\section{Summary}

Minimally invasive surgery is standard procedure for many operations. Further refinements include the introduction of robotic surgery which is still an emerging field especially in laparoscopic surgery. Since the successful introduction of the da Vinci Robotic Surgical System, the robotic approach in organ transplantation has become of great interest in both the live donor organ retrieval and the recipient operation. Robotic surgery for kidney, liver, and pancreas transplantation is feasible. Over 700 donor nephrectomies and 100 kidney transplantations have been performed already, and robotic surgery is standard in a small number of pioneer centers; however, larger series and most importantly randomized controlled trials for the highest evidence are needed. Longer warm ischemia time and higher costs limit these procedures at the moment.

(C) 2018 S. Karger GmbH, Freiburg

\section{Introduction}

During the last decades, minimally invasive surgery has become standard procedure in many operations. Further developments include robotic surgery which is an emerging field especially in laparoscopic surgery. Meanwhile a few robotic systems with various abilities and price tags have been developed by different companies.
The rapid development of both equipment including camera systems, insufflators for pneumoperitoneum, and instruments, as well as surgical techniques for minimally invasive approaches have changed surgery over the past few years. In addition to the benefits provided by conventional laparoscopic surgery, the robotic systems for robotic-assisted surgery (RAS) are supposed to help to overcome reduced visualization, restricted range of motion, and even physiological tremor of the surgeon [1]. Feasibility and safety in performing a challenging and complex procedure with RAS is given [2]; however, RAS if compared with conventional open surgery as well as conventional laparoscopic surgery is associated with much higher costs that come along with the inevitable use of specially designed high-end equipment and length of procedure including the time needed to set up the system in the operating room for every case.

With conventional laparoscopic surgical techniques, some very complex procedures such as organ transplantation have not been considered as suitable for minimally invasive surgery [3]; however, after the introduction of modern precise surgical robotic systems like the da Vinci Surgical System (daVSS) (Intuitive Surgical, Sunnyvale, CA, USA), the surgeons' ability has expanded and even organ transplantation is considered to be performed in a minimally invasive fashion with RAS [4].

The main advantages of the daVSS compared with conventional laparoscopic surgery are i) the 3-dimensional (3D) view which completely restores hand-eye coordination and even includes a possible $10 \times$ and $15 \times$ magnification of the operative field if needed, while the operative field remains steady with the camera driven by the surgeon who is doing the procedure; ii) the instruments provide a distal articulation similar to the human wrist (EndoWrist ${ }^{\circledR}$, Intuitive Surgical) with 7 degrees of freedom, thus EndoWrist totally avoids the fulcrum effect of conventional laparoscopic surgery; and iii) the physiological human tremor is eliminated by motion scaling which is achieved with the device tracking the surgeon's movements 1,300 times per second.

\section{KARGER}

() 2018 S. Karger GmbH, Freiburg
Univ.-Prof. Dr. med. Dr. h.c. Peter Schemmer, MBA 
Based on the features of RAS stated above, the minimally invasive approach in organ transplantation has become of great interest in both the live donor organ retrieval and the recipient operation, but suitability and cost effectiveness have to be carefully investigated.

In 1995, Ratner et al. [5] introduced the concept of minimally invasive live donor kidney graft retrieval. This totally laparoscopic approach was used in 2001 by Gruessner et al. [6] who then reported the first laparoscopic pancreatic graft retrieval in a live donor, followed by Soubrane et al. [7] who performed the first laparoscopic left lateral liver resection in a live donor for pediatric transplantation in 2006. Since 2002, the use of RAS has been steadily increasing in transplant surgery.

\section{Kidney Transplantation}

Kidney transplantation (KTx) is the treatment of choice in endstage renal disease. Kidney is the most frequently transplanted solid organ, and the most experience with RAS has been gained in both donors and recipients in the setting of living related KTx [8].

\section{Live Kidney Donation}

Previous research has clearly shown both superior survival of kidney grafts from live donors after transplantation and fewer postoperative complications $[9,10]$.

While the conventional surgical approach with a mini-incision for open live donor nephrectomy has been shown to significantly reduce morbidity compared to historic open approaches [11-14], laparoscopic transperitoneal donor nephrectomy has become standard procedure for the procurement of live donor kidneys due to better visibility of the operative field in many centers [9] being associated with a short hospital stay, less pain, and fast recovery after surgery in some studies $[15,16]$.

In the past decade, new developments and improvements in operating techniques and imaging, such as RAS, have been implemented. This has led to the implementation of robotic-assisted donor nephrectomy (RADN) in some centers [17]. The first series of 12 successful RADN were performed with daVSS [17]. Since then, over 700 RADNs have been reported (table 1).

\section{Surgical Procedure}

Briefly, for a left live donor nephrectomy, the patient is in a right lateral decubitus position supported with a cushioned beanbag and axillary roll. Adequate fixation of the patient on the operating table is mandatory, because any instability after docking the robotic system could jeopardize the safety of the procedure [4]. Transabdominal RADN is usually performed with 4 laparoscopic ports (3 8- mm and $112-\mathrm{mm}$ camera port, and if needed an additional $12-\mathrm{mm}$ assistant port) and 17 -cm infraumbilical incision [4].

Once the trocars are in place and the instruments inserted together with the optical system, the procedure is started with the mobilization of the left colon including the transection of the sple- nocolic ligament. A space is created between the left mesocolon and Gerota's fascia. This preparation allows bloodless exposure of the left kidney's anterior surface. Subsequently, the kidney is freed from its fatty capsule; the ureter is dissected free and cut distally where it crosses the iliac vessels. Before cutting the ureter, a Hemo-lok clip can be put distally on both the ureter and the gonadal vein. Now the renal vessels are exposed to its junction with the inferior vena cava and aorta. The renal vessels then are stapled or clipped close to the large vessels by the assistant surgeon. After rapid removal from the abdominal cavity, the kidney is rinsed with cold preservation solution.

Left kidneys are preferred live grafts because of the anatomical features of the right kidney which has a shorter length and greater fragility of its vein; however, the RADN procedure is the same with the live donor placed in the left decubitus position.

Usually, the patient is encouraged to ambulate the same day, and if no complications occur, the donor is discharged home on the second or third postoperative day [4].

\section{Results}

Tzvetanov et al. [4] analyzed a series of about 700 RADNs and reported only a limited number of complications. The most important complications, requiring conversion to open procedure, occurred at the beginning of the learning curve and included 3 cases of intraoperative renal artery stump bleeding and a single case of intraoperative renal vein laceration.

The initial graft survival and function rates and donor morbidity appeared to be very similar to the data from open living donor nephrectomy [18].

Recently, Janki et al. [9] compared RADN to hand-assisted retroperitoneoscopic donor nephrectomy (HARP) and standard laparoscopic kidney (LDN) procurement. There was a significantly longer median total operative time with RADN compared to both LDN and HARP. Further, warm ischemia time (WIT) in RADN was significantly longer as compared to all the other live organ donor procedures. Complication rate as well as graft and patient survival after 3 months were independent of the procedure. The results of this study are also comparable with other current studies describing RADN procedures for operative time [19], warm ischemia $[19,20]$, and length of hospital stay [19], which do not show clear superiority of RADN over the other modalities described.

The largest study published by Horgan et al. [17] including 250 living kidney donors shows that the mean operative time was strongly reduced with an increasing number of RADNs performed. Janki et al. [9] showed a significant improvement in total operative time after 60 RADNs performed, indicating the importance of the learning curve in RADN.

Up to now, approximately 700 cases of robotic living donor nephrectomy have been described in literature as compiled in table 1 [8].

Limitations that relate to the robotic system include prolonged set-up time and difficult instrument exchange which occur more frequently at the beginning of the learning curve [21]. 
The series presented by Janki et al. [9] showed that left-sided RADN is safe and feasible with good outcomes for donor, recipient, and graft survival after 3 months of follow-up. The RADN procedure might take longer; however, 3D imaging, better instrument movement, and comfort are gained. Although there is no scientific study evaluating the clinical pathway of robotic surgery training, a minimal caseload is necessary to maintain surgical robotic skills and technicity. For experienced endoscopically trained surgeons, the operative time will improve significantly and approximate the operative time of other surgical techniques [9].

Bhattu et al. [22] performed a randomized controlled trial with 54 kidney donors and compared RADN to LDN. They concluded that RADN is safe and associated with a better morbidity profile than LDN. The robotic approach provides technical ease and facilitates preservation of a longer length of the renal artery on the right side. The authors stated that left-sided RADN is associated with longer WIT but did not find any negative influence on graft outcome.

Taking into consideration all the data presented above, RADN appears to be feasible; however, with regard to WIT and higher costs, the procedure seems to be limited to certain case series, especially within high-volume centers.

\section{Kidney Transplantation Techniques}

Today's techniques in KTx include conventional laparoscopic (transperitoneal or retroperitoneal), robotic-assisted, as well as open minimal-access KTx [11].

Despite the advantages mentioned above, possible adverse effects such as prolonged WIT and operative time have to be considered. WIT is known to be a negative cofounder for graft injury [11, 23]. Recently, Marzouk et al. [11, 23] reported that anastomosis time $>29$ min significantly increases postoperative delayed graft function. Weissenbacher et al. [24] showed significant negative effects of prolonged anastomosis time $>30 \mathrm{~min}$ for patients and graft survival, and therefore robotic-assisted kidney transplantation (RAKT) should only be performed in high-volume centers with large expertise in RAS in order to avoid negative effects on the kidney graft due to long WIT and anastomosis time. Thus, strategies to minimize WIT in RAKT have to be developed. Menon et al. [25] reported a new technique for intraperitoneal cooling of the allograft with ice slush in order to reduce WIT.

Hoznek et al. [26] published a first and single case of robotic assistance during KTx in which an open access to the iliac fossa was established and dissection of the vessels with subsequent anastomosis was performed using the robot [8]. Later, the first complete RAKT was published in the US by Giulianotti et al. [27]. This operation took $230 \mathrm{~min}$ with a WIT of $50 \mathrm{~min}$. Boggi et al. [28] reported the first RAKT in Europe 2 years later [8]. During the last decades, laparoscopic KTx has been replaced by RAKT in some high-volume centers. Menon et al. [25] standardized RAKT and performed 50 cases purely robotically. While Menon et al. [25] used RAKT in normal-weight recipients, Tzventanov et al. [4] used RAS especially in obese patients.
Table 1. Robotic-assisted surgery in kidney transplantation (KTx)

\begin{tabular}{|c|c|c|c|c|}
\hline Author & Reference & $\begin{array}{l}\text { Live left } \\
\text { kidney retrieval }\end{array}$ & $\begin{array}{l}\text { Live right } \\
\text { kidney retrieval }\end{array}$ & $\mathrm{KTx}$ \\
\hline Abaza & [59] & 0 & 0 & 39 \\
\hline Bhattu & {$[22]$} & 9 & 6 & 0 \\
\hline Boggi & {$[28,51]$} & 0 & 0 & 2 \\
\hline Breda & {$[60]$} & 0 & 0 & 17 \\
\hline Cohen & {$[61]$} & 79 & 21 & 0 \\
\hline Galvani & {$[21]$} & 1 & 0 & 0 \\
\hline Giacomoni & {$[20]$} & 16 & 0 & 0 \\
\hline Giulianotti & {$[27]$} & 0 & 0 & 1 \\
\hline Gordon & {$[62]$} & 1 & 0 & 1 \\
\hline Gorodner & {$[63]$} & 209 & 4 & 0 \\
\hline Horgan & {$[17]$} & 254 & 19 & 0 \\
\hline Hoznek & {$[26]$} & 0 & 0 & 1 \\
\hline Hubert & {$[64]$} & 12 & 8 & 0 \\
\hline Janki & {$[65]$} & 59 & 0 & 0 \\
\hline Kaouk & {$[36]$} & 1 & 0 & 0 \\
\hline Laplace & {$[31]$} & 85 & 0 & 0 \\
\hline Liu & {$[19]$} & 0 & 5 & 0 \\
\hline Louis & {$[66]$} & 34 & 1 & 0 \\
\hline Meier & {$[67]$} & 0 & 0 & 17 \\
\hline Menon & {$[25]$} & 0 & 0 & 50 \\
\hline Oberholzer & {$[34]$} & 0 & 0 & 75 \\
\hline Renoult & {$[18]$} & 12 & 4 & 0 \\
\hline Sood & {$[68-70]$} & 0 & 0 & 160 \\
\hline Tsai & [29] & 0 & 0 & 10 \\
\hline Tzventanov & {$[4]$} & 0 & 0 & 70 \\
\hline
\end{tabular}

\section{Surgical Procedure}

Back table preparation for robotic implantation includes specific steps in order to facilitate orientation of the organ and minimize bleeding after reperfusion.

Transperitoneal KTx is carried out via 4 laparoscopic ports (2 $12-\mathrm{mm}$ and $27-\mathrm{mm}$ ports) and a $7-\mathrm{cm}$ midline incision for the hand port. The patient is placed in a $30^{\circ}$ Trendelenburg position with the right side elevated for transplantation in the right iliac fossa. The robotic system is docked into position at the patient's right leg [4].

After mobilization of the right colon, the right iliac vessels are exposed. Once the external iliac vein is completely dissected and clamped with bulldogs, a venotomy for end-to-side anastomosis with running suture is performed. Subsequently, a side-to-end arterial anastomosis is performed likewise. Clamps are removed for reperfusion of the graft. At this point, the pressure of the pneumoperitoneum is decreased to minimize a possible negative effect of high intra-abdominal pressure on graft perfusion. Finally, the ureter is anastomosed to the bladder.

Most of the studies reported in the literature have been performed transabdominally. Tsai et al. [29] recently reported initial experiences in robot-assisted retroperitoneal KTx with promising results.

Results

Menon et al. [25] have shown results with a mean creatinine at discharge of $1.3 \mathrm{mg} / \mathrm{dl}$ which is comparable with conventional 
techniques. There were no intraoperative and postoperative complications at 6-month follow-up. Breda et al. [30] applied regional hypothermia in 17 RAKTs with no major surgical intraoperative complication; however, delayed graft function, graft arterial thrombosis, and intraperitoneal hematoma appeared in single patients. A series of 100 RAKTs with $99 \%$ of immediate renal graft function recovery was published by Laplace et al. [31].

In obese patients, surgical site infections (SSI) were absent and results were similar to non-obese recipients [32]. These results show the importance of implementing new surgical techniques in obese KTx recipients that can prevent complications such as SSI. The authors describe their results in more than 70 RAKTs in obese patients and did not observe any SSI within the first 30 days after transplantation [4]. The hypothesis that RAS is a safe procedure in such patients is supported by data by Garcia-Roca et al. [33] showing excellent patient and graft survival with a renal function comparable to open techniques. This was also confirmed by Oberholzer et al. [34].

As WIT is crucial in KTx, the use of a robotic system for kidney implantation does not seem to be justified as the results do not show superiority to conventional KTx. Therefore, RAKT at the moment should be limited to obese patients who seem to clearly benefit from this method. Furthermore, besides transplantation, robot-assisted procedures have been described in KTx recipients for the management of surgical complications, such as cases of pyeloureterostomy for ureteral stricture [35], partial nephrectomy for the treatment of a renal mass in a transplanted kidney [36], transabdominal graft nephrectomy [37], and radical prostatectomy for prostate cancer treatment in kidney transplant recipients [38] with good results.

\section{Liver Transplantation}

Living donation is one of the tools to increase the donor pool thus reducing the lack of livers suitable for transplantation from deceased donors. Live donor right hepatectomy has become the most common procedure in living related adult-to-adult liver transplantation (LTx) and is a widely accepted alternative to deceased donor LTx $[11,39]$; however, there are concerns regarding the safety of healthy volunteer live organ donors [2]. Complication rates of living liver donors range between 16 and 34\% [40].

The laparoscopic approach for right lobe live liver donation seems to be advantageous since $30-50 \%$ of the complications in open cases are associated with trauma to the abdominal wall, i.e. hernia, bowel obstruction, and chronic abdominal discomfort [41] Studies on robotic-assisted live liver donation are compiled in table 2.

\section{Living-Donor Hepatectomy}

RAS techniques have shown advantages in patients undergoing major hepatectomy [42]. The first report of a robotic live donor right hepatectomy was by Giulianotti et al. [43] in 2012. A recent
Table 2. Roboticassisted surgery in liver transplantation

\begin{tabular}{llc}
\hline Author & Reference & Live liver retrieval \\
\hline Chen & {$[2]$} & 13 (right lobe) \\
Giulianotti & {$[43]$} & 1 (right lobe) \\
Wu & {$[71]$} & 1 (left lobe) \\
\hline
\end{tabular}

Table 3. Roboticassisted surgery in pancreas transplantation (PTx)

\begin{tabular}{llll}
\hline Author & Reference & $\begin{array}{l}\text { Live pancreas } \\
\text { retrieval }\end{array}$ & PTx \\
\hline Boggi & {$[52]$} & & 3 \\
$\begin{array}{l}\text { Horgan } \\
\text { Yeh }\end{array}$ & {$[49]$} & 1 & 1 \\
\hline
\end{tabular}

review suggested that robotic liver resection is at least comparable to both open and laparoscopic procedures based on outcome [44]. No differences between robotic and open donor right hepatectomy but less postoperative pain control associated with pneumonia in favor of the robotic procedure were described $[2,4]$.

\section{Surgical Procedure}

In supine $20^{\circ}$ reverse Trendelenburg position with parted legs, the procedure is performed using 3 trocars $(12 \mathrm{~mm})$ for the robotic arms, 2 assistant ports (12 and $5 \mathrm{~mm}$ ), and a camera port [44]. Usually, the liver is freed from the hepatic ligaments and the hilum dissected free together with both the right hepatic artery and portal vein for liver right donor hepatectomy. This and the other steps including parenchymal dissection, division of vessels, cholangiography, and sonography are very much standard irrespective of the approach. The donor graft is retrieved through a $8-$ to $10-\mathrm{cm}$ Pfannenstiel incision and subsequently rinsed with cold perfusion solution [4].

\section{Results}

While the operative time in live donor right hepatectomy is significantly longer compared with open procedures, there is no difference in complication rates, blood loss, and postoperative function of the liver remnant $[2,45]$. Decreased overall morbidity and intensive care unit and hospital stay are in favor of laparoscopic procedures while the operation per se adds tremendously to treatment cost, especially in the case of robotic systems being used. Taking into consideration the higher costs as well as the longer operating time, robotic-assisted donor right hepatectomy is not advantageous over conventional laparoscopic approaches [45].

Although the procedure should only be performed by experienced surgeons, robotic surgery might play an important role in establishing a standard procedure for minimally invasive liver donor surgery and especially in living liver donation.

\section{Pancreas Transplantation}

Pancreatic transplantation (PTx) is the only method to restore physiological glycemic control and prevent progression of com- 
plications in diabetic patients [46]. Refinements in surgical technique and immunosuppressive therapy have considerably improved outcome; however, the complication rate remains still at about 25\% [47].

\section{Pancreas Donation}

Live pancreatic donation for transplantation is very rare [48] (table 3). Distal live donor pancreatectomy with spleen preservation [8] is meant to decrease the morbidity and mortality of diabetic patients who have potential donors [34]. Since PTx is simultaneously performed with $\mathrm{KTx}$, a possible advantage of minimally invasive surgery for live donation is that once the left kidney is removed, the inferior border of the pancreatic tail is already partially dissected [8]. The first robotic hand-assisted simultaneous nephrectomy and distal pancreatectomy was described in 2007 by Horgan et al. [49].

\section{Surgical Procedure}

Horgan et al. [49] reported a single case of RADN with daVSS for live donor pancreatic tail retrieval for transplantation. Briefly, the splenic artery and vein were isolated and divided distally close to the hilum of the spleen and were isolated to the celiac trunk and portal vein, respectively. The parenchymal transection was performed at the junction between the body and the head of the pancreas. The organ was removed and underwent back table preparation subsequent to cold preservation [4].

\section{Pancreatic Transplantation}

PTx still remains the treatment of choice for patients suffering from insulin-dependent type I diabetes. While there is a great number of potential recipients [50], PTx continues to be offered only to highly affected individuals who have poor quality of life under conventional insulin therapy [51]. The laparoscopic approach to PTx has improved outcome [52]; well-known limitations in conventional laparoscopic surgery restrict the use in PTx to experts in this field [3]. Boggi et al. [51] have shown how to overcome these limitations with RAS for PTx.

Yeh et al. [53] performed the first RAS for pancreas after KTx in 1 severely obese patient. Excellent metabolic control was achieved, and the patient remained in a nondiabetic status during the followup period.

However, taking into consideration the longer WIT as well as higher costs and operating time, robotic-assisted pancreatic donation and transplantation are not superior to conventional open approaches.

\section{Surgical Procedure}

Careful in situ preparation during the cadaveric donor organ retrieval is required to avoid bleeding at transplantation [52]. During the back table operation, the pancreatic graft's vasculature must be reconstructed with a donor-Y-iliac graft as used in standard conventional PTx. A small midline incision is needed to insert the graft into the abdomen. Subsequently, the pancreas is placed behind the right colon. The proximal vena cava is anastomosed to the superior mesenteric vein due to larger caliber and easier handling. Donor-Y-graft is anastomosed to the recipient's common iliac artery. The duodeno-jejunal anastomosis is performed open with a Roux-en-Y loop reconstruction.

In contrast to standard open simultaneous $\mathrm{P} / \mathrm{KTx}$, Fridell et al. [54] placed both grafts on the right side of the recipient without modifying the patient's position; however, for the uretero-vesical anastomosis, repositioning of the patient and the robotic system would have been needed. Due to time limitations, an open approach for this step is recommended.

\section{Results}

PTx with daVSS is feasible [51, 55]; however, the benefits of RAS in this procedure are limited [51] and today's standard must be changed towards the use of a robotic system with major steps still performed in an open fashion [56]. For cooling the graft during PTx, a pancreas jacket has been developed [57].

\section{Conclusion}

Robotic-assisted transplantation is feasible and has already been performed for KTx, PTx, and uterus transplantation by a few pioneers in the field of RAS. While there are major obstacles in the recipient operation, robotic-assisted live kidney retrieval has become standard procedure in some centers. Despite the enthusiasm for the emerging RAS in transplantation, widespread use is limited due to current costs, longer operating times, and, in what is most crucial in transplantation, longer WIT $[34,58]$.

In the future, the issues of WIT and cold storage must be carefully addressed in the setting of RAS for transplantation. The gold standards and requirements for the highly standardized conventional technique must also remain valid for RAS.

The use of RAS in transplantation has to be carefully considered in high-performing centers but does not show clear superiority to conventional transplantation techniques according to the current literature.

Since, to date, cases in which the entire operation has been performed using RAS are rare in transplantation surgery, a comparison in between conventional laparoscopic and RAS cases with a focus on transplantation is not conducive; however, successful transplantation seems to be feasible using the synergies between RAS and conventional laparoscopic surgery.

\section{Disclosure Statement}

The authors have no conflict of interest to declare. 


\section{References}

1 Giulianotti PC, Coratti A, Angelini M, Sbrana F, Cecconi S, Balestracci T, Caravaglios G: Robotics in general surgery: personal experience in a large community hospital. Arch Surg 2003;138:777-784.

2 Chen PD, Wu CY, Hu RH, Ho CM, Lee PH, Lai HS, Lin MT, Wu YM: Robotic liver donor right hepatectomy: a pure, minimally invasive approach. Liver Transpl 2016;22:1509-1518.

3 Rosales A, Salvador JT, Urdaneta G, Patino D Montlleo M, Esquena S, Caffaratti J, Ponce de Leon J, Guirado L, Villavicencio H: Laparoscopic kidney transplantation. Eur Urol 2010;57:164-167.

4 Tzvetanov I, Bejarano-Pineda L, Giulianotti PC, Jeon H, Garcia-Roca R, Bianco F, Oberholzer J, Benedetti E: State of the art of robotic surgery in organ transplantation. World J Surg 2013;37:2791-2799.

5 Ratner LE, Ciseck LJ, Moore RG, Cigarroa FG, Kaufman HS, Kavoussi LR: Laparoscopic live donor nephrectomy. Transplantation 1995;60:1047-1049.

6 Gruessner RW, Kandaswamy R, Denny R: Laparoscopic simultaneous nephrectomy and distal pancreatectomy from a live donor. J Am Coll Surg 2001;193: 333-337.

7 Soubrane O, de Rougemont O, Kim KH, Samstein B Mamode N, Boillot O, Troisi RI, Scatton O, Cauchy F, Lee SG, Griesemer A, Ahmed Z, Clavien PA, Cherqui D: Laparoscopic living donor left lateral sectionectomy: a new standard practice for donor hepatectomy. Ann Surg 2015;262:757-761; discussion 761-763.

8 Levi Sandri GB, de Werra E, Masciana G, Guerra F, Spoletini G, Lai Q: The use of robotic surgery in abdominal organ transplantation: a literature review. Clin Transplant 2017;31:DOI: 10.1111/ctr.12856.

9 Janki S, Klop KWJ, Hagen SM, Terkivatan T, Betjes MGH, Tran TCK, Ijzermans JNM: Robotic surgery rapidly and successfully implemented in a high volume laparoscopic center on living kidney donation. Int J Med Robot 2017;13:10.

10 Horvat LD, Shariff SZ, Garg AX; Donor Nephrectomy Outcomes Research (DONOR) Network: Global trends in the rates of living kidney donation. Kidney Int 2009; 75:1088-1098.

11 Wagenaar S, Nederhoed JH, Hoksbergen AWJ, Bonjer HJ, Wisselink W, van Ramshorst GH: Minimally invasive, laparoscopic, and robotic-assisted techniques versus open techniques for kidney transplant recipients: a systematic review. Eur Urol 2017;72:205-217.

12 Fonouni H, Mehrabi A, Golriz M, Zeier M, MullerStich BP, Schemmer P, Werner J: Comparison of the laparoscopic versus open live donor nephrectomy: an overview of surgical complications and outcome. Langenbecks Arch Surg 2014;399:543-551.

13 Greco F, Hoda MR, Alcaraz A, Bachmann A, Hakenberg OW, Fornara P: Laparoscopic living-donor nephrectomy: analysis of the existing literature. Eur Urol 2010;58:498-509.

14 Dols LF, Kok NF, Ijzermans JN: Live donor nephrectomy: a review of evidence for surgical techniques. Transpl Int 2010;23:121-130.

15 Kok NF, Lind MY, Hansson BM, Pilzecker D, Mertens zur Borg IR, Knipscheer BC, Hazebroek EJ, Dooper IM, Weimar W, Hop WC, Adang EM, van der Wilt GJ, Bonjer HJ, van der Vliet JA, Ijzermans JN: Comparison of laparoscopic and mini incision open donor nephrectomy: single blind, randomised controlled clinical trial. BMJ 2006;333:221.

16 Dols LF, Kok NF, d'Ancona FC, Klop KW, Tran TC Langenhuijsen JF, Terkivatan T, Dor FJ, Weimar W, Dooper IM, Ijzermans JN: Randomized controlled trial comparing hand-assisted retroperitoneoscopic versus standard laparoscopic donor nephrectomy. Transplantation 2014;97:161-167.
17 Horgan S, Galvani C, Gorodner MV, Jacobsen GR, Moser F, Manzelli A, Oberholzer J, Fisichella MP, Bogetti D, Testa G, Sankary HN, Benedetti E: Effect of robotic assistance on the 'learning curve' for laparoscopic hand-assisted donor nephrectomy. Surg Endosc 2007;21:1512-1517.

18 Renoult E, Hubert J, Ladriere M, Billaut N, Mourey E, Feuillu B, Kessler M: Robot-assisted laparoscopic and open live-donor nephrectomy: a comparison of donor morbidity and early renal allograft outcomes. Nephrol Dial Transplant 2006;21:472-477.

19 Liu XS, Narins HW, Maley WR, Frank AM, Lallas CD: Robotic-assistance does not enhance standard laparoscopic technique for right-sided donor nephrectomy. JSLS 2012;16:202-207.

20 Giacomoni A, Di Sandro S, Lauterio A, Mangoni I, Mihaylov P, Concone G, Tripepi M, Poli C, Cusumano C, De Carlis L: Initial experience with robot-assisted nephrectomy for living-donor kidney transplantation: feasibility and technical notes. Transplant Proc 2013; 45:2627-2631.

21 Galvani CA, Garza U, Leeds M, Kaul A, Echeverria A, Desai CS, Jie T, Diana R, Gruessner RW: Single-incision robotic-assisted living donor nephrectomy: case report and description of surgical technique. Transpl Int 2012;25:e89-92.

22 Bhattu AS, Ganpule A, Sabnis RB, Murali V, Mishra S, Desai M: Robot-assisted laparoscopic donor nephrectomy vs standard laparoscopic donor nephrectomy: a prospective randomized comparative study. J Endourol 2015;29:1334-1340.

23 Marzouk K, Lawen J, Alwayn I, Kiberd BA: The impact of vascular anastomosis time on early kidney transplant outcomes. Transplant Res 2013;2:8.

24 Weissenbacher A, Oberhuber R, Cardini B, Weiss S, Ulmer H, Bosmuller C, Schneeberger S, Pratschke J, Ollinger R: The faster the better: anastomosis time influences patient survival after deceased donor kidney transplantation. Transpl Int 2015;28:535-543.

25 Menon M, Sood A, Bhandari M, Kher V, Ghosh P, Abaza R, Jeong W, Ghani KR, Kumar RK, Modi P, Ahlawat R: Robotic kidney transplantation with regional hypothermia: a step-by-step description of the Vattikuti Urology Institute-Medanta technique (IDEAL phase 2a). Eur Urol 2014;65:991-1000.

26 Hoznek A, Zaki SK, Samadi DB, Salomon L, Lobontiu A, Lang P, Abbou CC: Robotic assisted kidney transplantation: an initial experience. J Urol 2002;167: 1604-1606.

27 Giulianotti P, Gorodner V, Sbrana F, Tzvetanov I, Jeon H, Bianco F, Kinzer K, Oberholzer J, Benedetti E: Robotic transabdominal kidney transplantation in a morbidly obese patient. Am J Transplant 2010;10: 1478-1482.

28 Boggi U, Vistoli F, Signori S, D’Imporzano S, Amorese G, Consani G, Guarracino F, Melfi F, Mussi A, Mosca F: Robotic renal transplantation: first European case. Transpl Int 2011;24:213-218.

29 Tsai MK, Lee CY, Yang CY, Yeh CC, Hu RH, Lai HS: Robot-assisted renal transplantation in the retroperitoneum. Transpl Int 2014;27:452-457.

30 Breda A, Territo A, Gausa L, Rodriguez-Faba O, Caffaratti J, de Leon JP, Guirado L, Facundo C, Guazzieri M, Guttilla A, Villavicencio H: Robotic kidney transplantation: one year after the beginning. World J Urol 2017;35:1507-1515.

31 Laplace B, Ladriere M, Claudon M, Eschwege P, Kessler M, Hubert J: Robotic assisted laparoscopic living donor nephrectomy: preoperative assessment and results of 100 cases. Prog Urol 2014;24:288-293.
32 Lynch RJ, Ranney DN, Shijie C, Lee DS, Samala N, Englesbe MJ: Obesity, surgical site infection, and outcome following renal transplantation. Ann Surg 2009; 250:1014-1020.

33 Garcia-Roca R, Garcia-Aroz S, Tzvetanov I, Jeon H, Oberholzer J, Benedetti E: Single center experience with robotic kidney transplantation for recipients with BMI of $40 \mathrm{~kg} / \mathrm{m}^{2}$ or greater: a comparison with the UNOS Registry. Transplantation 2017;101:191-196.

34 Oberholzer J, Giulianotti P, Danielson KK, Spaggiari M, Bejarano-Pineda L, Bianco F, Tzvetanov I, Ayloo S, Jeon H, Garcia-Roca R, Thielke J, Tang I, Akkina S, Becker B, Kinzer K, Patel A, Benedetti E: Minimally invasive robotic kidney transplantation for obese patients previously denied access to transplantation. Am J Transplant 2013;13:721-728.

35 Orvieto MA, Chien GW, Shalhav AL, Tolhurst SR, Rapp DE, Galocy RM, Harland RC: Case report: robotassisted laparoscopic pyeloureterostomy in a transplanted kidney with ureteral stricture. J Endourol 2006; 20:31-32.

36 Kaouk JH, Spana G, Hillyer SP, White MA, Haber GP Goldfarb D: Robotic-assisted laparoscopic partial nephrectomy for a $7-\mathrm{cm}$ mass in a renal allograft. Am J Transplant 2011;11:2242-2246.

37 Mulloy MR, Tan M, Wolf JH, D’Annunzio SH, Pollinger HS: Robotic trans-abdominal transplant nephrectomy for a failed renal allograft. Am J Transplant 2014; 14:2883-2886.

38 Polcari AJ, Allen JC, Nunez-Nateras R, Mmeje CO, Andrews PE, Milner JE, Castle EP, Woods ME: Multicenter experience with robot-assisted radical prostatectomy in renal transplant recipients. Urology 2012; 80:1267-1272.

39 Ninomiya M, Shirabe K, Facciuto ME, Schwartz ME Florman SS, Yoshizumi T, Harimoto N, Ikegami T, Uchiyama H, Maehara Y: Comparative study of living and deceased donor liver transplantation as a treatment for hepatocellular carcinoma. J Am Coll Surg 2015;220:297-304.e3.

40 Kim SH, Kim YK: Improving outcomes of livingdonor right hepatectomy. Br J Surg 2013;100:528-534.

41 Abecassis MM, Fisher RA, Olthoff KM, Freise CE, Rodrigo DR, Samstein B, Kam I, Merion RM; A2ALL Study Group: Complications of living donor hepatic lobectomy - a comprehensive report. Am J Transplant 2012;12:1208-1217.

42 Tsung A, Geller DA, Sukato DC, Sabbaghian S, Tohme S, Steel J, Marsh W, Reddy SK, Bartlett DL: Robotic versus laparoscopic hepatectomy: a matched comparison. Ann Surg 2014;259:549-555.

43 Giulianotti PC, Tzvetanov I, Jeon H, Bianco F, Spaggiari M, Oberholzer J, Benedetti E: Robot-assisted right lobe donor hepatectomy. Transpl Int 2012;25:e5-9.

44 Giulianotti PC, Bianco FM, Daskalaki D, GonzalezCiccarelli LF, Kim J, Benedetti E: Robotic liver surgery: technical aspects and review of the literature. Hepatobiliary Surg Nutr 2016;5:311-321.

45 Daskalaki D, Gonzalez-Heredia R, Brown M, Bianco FM, Tzvetanov I, Davis M, Kim J, Benedetti E, Giulianotti PC: Financial impact of the robotic approach in liver surgery: a comparative study of clinical outcomes and costs between the robotic and open technique in a single institution. J Laparoendosc Adv Surg Tech A 2017;27:375-382.

46 Tzvetanov I, D’Amico G, Bejarano-Pineda L, Benedetti E: Robotic-assisted pancreas transplantation: where are we today? Curr Opin Organ Transplant 2014;19: $80-82$. 
47 Banga N, Hadjianastassiou VG, Mamode N, Calder F, Olsburgh J, Drage M, Sammartino C, Koffman G, Taylor J: Outcome of surgical complications following simultaneous pancreas-kidney transplantation. Nephrol Dial Transplant 2012;27:1658-1663.

48 Kirchner VA, Finger EB, Bellin MD, Dunn TB, Gruessner RW, Hering BJ, Humar A, Kukla AK, Matas AJ, Pruett TL, Sutherland DE, Kandaswamy R: Longterm outcomes for living pancreas donors in the modern era. Transplantation 2016;100:1322-1328.

49 Horgan S, Galvani C, Gorodner V, Bareato U, Panaro F, Oberholzer J, Benedetti E: Robotic distal pancreatectomy and nephrectomy for living donor pancreas-kidney transplantation. Transplantation 2007;84:934-936.

50 Sutherland DE, Gruessner RW, Dunn DL, Matas AJ, Humar A, Kandaswamy R, Mauer SM, Kennedy WR, Goetz FC, Robertson RP, Gruessner AC, Najarian JS: Lessons learned from more than 1,000 pancreas transplants at a single institution. Ann Surg 2001;233:463501.

51 Boggi U, Signori S, Vistoli F, Amorese G, Consani G, De Lio N, Perrone V, Croce C, Marchetti P, Cantarovich D, Mosca F: Current perspectives on laparoscopic robot-assisted pancreas and pancreas-kidney transplantation. Rev Diabet Stud 2011;8:28-34.

52 Boggi U, Signori S, Vistoli F, D’Imporzano S, Amorese G, Consani G, Guarracino F, Marchetti P, Focosi D, Mosca F: Laparoscopic robot-assisted pancreas transplantation: first world experience. Transplantation 2012;93:201-206.

53 Yeh CC, Spaggiari M, Tzvetanov I, Oberholzer J: Robotic pancreas transplantation in a type 1 diabetic patient with morbid obesity: a case report. Medicine (Baltimore) 2017;96:e5847.

54 Fridell JA, Shah A, Milgrom ML, Goggins WC, Leapman SB, Pescovitz MD: Ipsilateral placement of simultaneous pancreas and kidney allografts. Transplantation 2004;78:1074-1076.
55 Oberholzer J, Tzvetanov I, Mele A, Benedetti E: Laparoscopic and robotic donor pancreatectomy for living donor pancreas and pancreas-kidney transplantation. J Hepatobiliary Pancreat Sci 2010;17:97-100.

56 Diamantis T, Tsiminikakis N, Skordylaki A, Samiotaki F, Vernadakis S, Bongiorni C, Tsagarakis N, Marikakis F, Bramis I, Bastounis E: Alterations of hemostasis after laparoscopic and open surgery. Hematology 2007; 12:561-570.

57 Navarro AP, Sohrabi S, Colechin E, Griffiths C, Talbot D, Soomro NA: Evaluation of the ischemic protection efficacy of a laparoscopic renal cooling device using renal transplantation viability assessment criteria in a porcine model. J Urol 2008;179:1184-1189.

58 Territo A, Mottrie A, Abaza R, Rogers C, Menon M, Bhandari M, Ahlawat R, Breda A: Robotic kidney transplantation: current status and future perspectives. Minerva Urol Nefrol 2017;69:5-13.

59 Abaza R, Ghani KR, Sood A, Ahlawat R, Kumar RK, Jeong W, Bhandari M, Kher V, Menon M: Robotic kidney transplantation with intraoperative regional hypothermia. BJU Int 2014;113:679-681.

60 Breda A, Territo A, Gausa L, Tugcu V, Alcaraz A, Musquera M, Decaestecker K, Desender L, Stockle M, Janssen M, Fornara P, Mohammed N, Siena G, Serni S, Guirado L, Facundo C, Doumerc N: Robot-assisted kidney transplantation: the European experience. Eur Urol 2018;73:273-281.

61 Cohen AJ, Williams DS, Bohorquez H, Bruce DS, Carmody IC, Reichman T, Loss GE Jr: Robotic-assisted laparoscopic donor nephrectomy: decreasing length of stay. Ochsner J 2015;15:19-24.

62 Gordon ZN, Angell J, Abaza R: Completely intracorporeal robotic renal autotransplantation. J Urol 2014; 192:1516-1522.
63 Gorodner V, Horgan S, Galvani C, Manzelli A, Oberholzer J, Sankary H, Testa G, Benedetti E: Routine left robotic-assisted laparoscopic donor nephrectomy is safe and effective regardless of the presence of vascular anomalies. Transpl Int 2006;19:636-640.

64 Hubert J, Siemer S: Nephrectomy, donor nephrectomy, and partial kidney resection: indications for robot-assisted renal surgery. Urologe A 2008;47:425426, 428-430.

65 Janki S, Dor FJ, IJzermans JN: Surgical aspects of live kidney donation: an updated review. Front Biosci (Elite Ed) 2015;7:346-365.

66 Louis G, Hubert J, Ladriere M, Frimat L, Kessler M Robotic-assisted laparoscopic donor nephrectomy for kidney transplantation. An evaluation of 35 procedures. Nephrol Ther 2009;5:623-630.

67 Meier RPH, Piller V, Hagen ME, Joliat C, Buchs JB Nastasi A, Ruttimann R, Buchs NC, Moll S, Vallee JP, Lazeyras F, Morel P, Buhler L: Intra-abdominal cooling system limits ischemia-reperfusion injury during robot-assisted renal transplantation. Am J Transplant 2018;18:53-62.

68 Sood A, Ghosh P, Menon M, Jeong W, Bhandari M, Ahlawat R: Robotic renal transplantation: current status. J Minim Access Surg 2015;11:35-39.

69 Sood A, McCulloch P, Dahm P, Ahlawat R, Jeong W, Bhandari M, Menon M: Ontogeny of a surgical technique: robotic kidney transplantation with regional hypothermia. Int J Surg 2016;25:158-161.

70 Sood A, Jeong W, Ahlawat R, Abdollah F, Sammon JD, Bhandari M, Menon M: Minimally invasive renal autotransplantation. J Surg Oncol 2015;112:717-722.

71 Wu G, Li Q, Zhao Q, Wang W, Shi H, Wang M, Zheng J, Li M, Fan D: Robotic-assisted live donor ileal segmentectomy for intestinal transplantation. Transplant Direct 2017;3:e215. 